\title{
Pharmacy students' self-reported attitudes, beliefs and behaviours about communicating with patients, measured over time
}

\author{
BERNADETTE A.M. CHEVALIER ${ }^{1 *}$ https://orcid.org/0000-0003-2809-1170 \\ BERNADETTE M. WATSON ${ }^{2}$ https://orcid.org/0000-0003-2419-7752 \\ WILLIAM NEIL COTTRELL ${ }^{3}$ \\ ${ }^{1}$ School of Pharmacy, The University of Queensland, Woolloongabba, Australia \\ ${ }^{2}$ Department of English, The Hong Kong Polytechnic University, Kowloon, Hong Kong \\ ${ }^{3}$ Faculty of Health and Behavioural Sciences, The University of Queensland, Australia
}

\begin{abstract}
Background: Pharmacy students receive training to effectively communicate with patients about their medications.

Objectives: A theory-based approach (Communication Accommodation Theory [CAT]) was used to investigate the impact of communication skills' tutorials on Pharmacy students' self-reported attitudes, beliefs and behaviours in patient communication.
\end{abstract}

Methods: Final year Pharmacy students completed an online, 30-item, patient-centred communication survey at three points in time, before and after attending three CAT-based tutorials (Survey \#1 and Survey \#2). Survey \#3 was distributed six to twelve months into students' intern training year (post-graduation). Differences between participants' responses over time were measured and analysed.

Results: Response rates were 78\% for Survey \#1, 84\% for Survey \#2, and 28\% for Survey \#3. Further analysis indicated that Survey \#3 respondents were not statistically different from the larger sample size. Key areas changed from baseline (Survey \#1) to post tutorials (Survey \#2) and were sustained well into Pharmacy students' intern year (Survey \#3).

Conclusions: This novel research indicated growing awareness and retention of key communication behaviours over time.

Keywords: Communication, Communication Accommodation Theory (CAT), Patient-centred Communication Tool, Pharmacy Student

\section{Introduction}

All health professionals including pharmacists must have effective communication skills to provide high quality patient care (World Health Organisation, 2003). Conversely, poor communication health provider exchanges with patients have been associated with lower patient satisfaction, treatment non-adherence and negative clinical outcomes (Zolnierek \& Dimatteo, 2009). In addition, the role of pharmacists in many countries has expanded to include advanced clinical skills such as prescriptive authority, ability to requisition laboratory tests, conduct physical assessments and provide immunisations (Tonna et al.,
2007; Law et al., 2012; Canadian Pharmacists' Association, 2018). However, as well as possessing competent clinical skills, pharmacists must communicate effectively with other healthcare professionals and especially with patients and their caregivers (Babinec et al., 2010; Murad, Chatterley, \& Guirguis, 2014). The importance of effective communication with 'patients, authorised representatives, healthcare team members and other healthcare professionals' is emphasised throughout the professional standards of practice developed for Australian pharmacists (Pharmaceutical Society of Australia, 2017).

${ }^{*}$ Correspondence: Dr. Bernadette A.M. Chevalier, School of Pharmacy, The University of Queensland, Australia, Level 4, 20 Cornwall St, Woolloongabba, Australia, 4102.Tel: +1 780819 0031.E-mail: b.chevalier@uq.edu.au 
A recent United States (US) publication comparing opinions of practicing pharmacists and final year Pharmacy students on preparedness for practice highlighted differences in opinions on how well Pharmacy students communicated with patients. Final year Pharmacy students and new graduates tended to overrate their abilities to communicate effectively with patients compared to the pharmacists (O'Brien, Flowers, $\&$ Stowe, 2017). These findings are similar to those found by Kairuz and colleagues and underline the importance of Pharmacy students having sufficient training in communication skills to ensure their communication competency at entry to practice (Kairuz, Noble, \& Shaw, 2010).

To address these communication development needs, Pharmacy schools typically include communication skills training throughout their Pharmacy curriculum (Jin et al., 2018). A variety of approaches are used to teach communication skills to Pharmacy students, and include communication as standalone courses (Buring, Kirby, \& Conrad, 2007; Hyvärinen et al., 2008; Trujillo et al., 2016; Jin et al., 2018). Alternatively communication skills can be integrated within the therapeutic topics (Blom et al., 2011; Katoue \& Al Haqan, 2013; Jin et al., 2018) or may be featured as a combination of the two (Hardin et al., 2012). In addition, most of these researchers also included laboratories or workshops for Pharmacy students to further develop their communication skills (Buring et al., 2007; Hyvärinen et al., 2008; Hardin et al., 2012; Trujillo et al., 2016; Jin et al., 2018).

At The University of Queensland (UQ), Pharmacy students receive communication skills training mainly through tutorials that reinforce theory and provide an opportunity for experiential learning. Communication skills training begins in the first year when students are introduced to a systematic approach to patient communication, and then this framework is built upon in subsequent years. This process of learning how to conduct patient counselling in a stepwise approach has benefits for Pharmacy students in their first year or two of training as it helps them organise conversations with patients to ensure important clinical points are covered in their exchanges (Buring et al., 2007). As Pharmacy students' therapeutic competence grows, relying on a rigid methodical approach can lead to one-way conversations with patients which limits the effectiveness of the communication exchange. This tendency for pharmacists to adopt and adhere to a procedural format in conversations with patients is not uncommon. Researchers have described pharmacists as task driven in the way in which they communicate with patients, and often this is in response to the time pressures they experience in the workplace (Braaf et al., 2015; Chevalier et al., 2017a). However, being overly task driven can result in a provider-centric process that meets the needs and goals of the healthcare professional, rather than the patient. In this situation, pharmacists, intent on efficiency, might convey medication information unidirectionally to patients and discourage patient engagement or two-way conversations in order to save time. In contrast, patient-centred approaches focus on patient needs or goals for that conversation (Braaf et al., 2015; Chevalier et al., 2017a).

This research team developed a new patient-centred communication tutorial (see Tutorial \#1 in Figure 1). The rationale for its development arose from concerns that final year UQ Pharmacy students were overly reliant on procedure-driven communication processes, that may in turn, lead to Pharmacy students developing providercentric communication practices.

The tutorial contents were informed by the first author's Ph.D. research (Chevalier, 2017b), and it was piloted with 201 final year UQ Pharmacy students in August and September 2016. Communication Accommodation Theory (CAT) was the theoretical framework underpinning the research and used in the development of the tutorial and in the interpretation and analysis of the pharmacist-patient interaction role plays.

CAT is a psychosocial framework that examines behavioural, motivational and emotional processes underlying communication exchanges and proposes that individuals' goals for any interaction drive their behaviour (Giles, 2008). Behaviour is often described as being either accommodative where speakers adjust their speech to bring themselves closer to others linguistically, or non-accommodative where they do not (Gasiorek \& Giles, 2012).

CAT suggests that there are five strategies that can be used to facilitate effective conversations. These include approximation, interpretability, discourse management, emotional expression and interpersonal control (Giles, 2008). Approximation deals with how speakers produce speech and match another's' speech volume, pace and accent (Coupland et al., 1988). Interpretability strategies include the avoidance of jargon so that speakers can understand what is being said. Discourse management focuses on communication behaviours such as listening intently, asking open-ended questions or redirecting topics (Jones, Woodhouse, \& Rowe, 2007). Emotional expression includes appropriate concern and reassurance in response to patients' emotional needs (Watson \& Gallois, 1999). Interpersonal control strategies used by pharmacists aim to encourage and empower patients to take an active role in managing their own health and medications (Jones et al., 2007).

CAT had been shown to be amenable to practical application in the pharmacist-patient communication context (Chevalier, 2017b). Therefore, the research team chose to investigate its application in communication skills training for Pharmacy students within the academic setting. CAT strategies were found to be sufficiently comprehensive (Chevalier, 2017b) and could be integrated into a learning experience where students receive peer feedback and are encouraged to reflect on their communication behaviours. The importance of using a comprehensive communication framework such as CAT is that it provides the students with insights into why communication behaviours occur and why miscommunication is common. 
The tutorial piloted in 2016 was not formally evaluated; however, Pharmacy students provided positive feedback in verbal and written format after the tutorial was held. Because the pilot was well received, two additional final year communication tutorials were revised by integrating CAT communication strategies and their corresponding behaviours. The research team wanted to investigate whether these three CAT-based communication skills' tutorials impacted Pharmacy students' self-reported attitudes, beliefs and behaviours in communicating with patients. The following research objectives were intended to address this overall goal:

1. To determine whether there were changes in Pharmacy students' self-reported attitudes, beliefs and behaviours in communicating with patients before and immediately after participating in the three tutorials (Survey \#1 and Survey \#2);

2. To ascertain whether Pharmacy students' selfreported attitudes, beliefs and behaviours in communicating with patients changed after six months into their intern training year, postgraduation (Survey \#3);

3. To validate the CAT-based questionnaire in the UQ's Pharmacy student population.

\section{Methods}

The University of Queensland's Institutional Human Ethics Committee (2017001089) approved the study. All participants provided informed consent by completing an online consent form prior to responding to the first survey. This was a quasi-experimental study (Campbell \& Cook, 1979) that investigated the impact of three communication skills' tutorials for a single group of final year Pharmacy students using an on-line survey administered at three time points, before and after completing the tutorials and then again in their intern training year, post-graduation.

\section{Recruitment and data collection}

This study took place at the School of Pharmacy, UQ. Eligible participants were interested fourth year (final year) Pharmacy students enrolled in semester two in 2017. Participants completed an online survey at three time points:

1. Prior to the commencement of the three tutorials (Survey \#1);

2. Immediately after the three tutorials were completed (Survey \#2);

3. Six to twelve months into participants' intern training year, post-graduation (Survey \#3).

Checkbox Survey was the online survey platform used for this study (Checkbox6, 2017). Approximately 10-15 minutes were allotted within the tutorials to complete Survey \#1 and \#2, followed by two bi-weekly email reminders. Pharmacy students who completed both Survey \#1 and \#2 were eligible to complete Survey \#3. These students received an electronic link to Survey \#3 (September 2018) which was followed up by four biweekly reminders (October-November 2018). The first author, who did not participate in any student assessment for this course, provided students with information about the research, links to the survey, and conducted all follow-up communications.

\section{Communication skills tutorials}

The three tutorials held from 1st September, 2017 to 6th October, 2017 were each given to 12 groups of 20-25 students. The first author delivered all of the first tutorials and most of the third tutorials (8/12 groups) while a Ph.D. student trained by the first author delivered the third tutorial to the remaining four groups of Pharmacy students. Another member of the research team led all of the second tutorials.

\section{Figure 1: Key features for each tutorial}

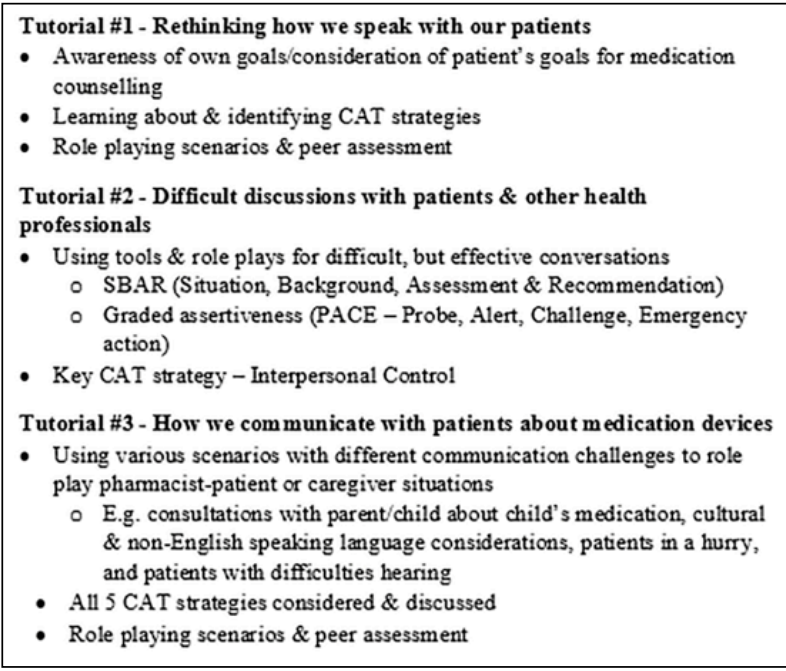

All tutorials contained the following learning strategies :

1. Reflection: For example, Tutorial \#1 used a modified THINK-PAIR-SHARE exercise (Kaddoura, 2013) to build awareness of how a person's goals direct their communication behaviours. Pharmacy students were first asked to think about and then discuss their own goals for medication counselling in pairs. Then, students were asked to consider what patients' goals might be. These were later discussed in the larger tutorial group

2. Active learning: Humorous pop culture videos chosen to reflect non-accommodative CAT strategies were used to demonstrate how poor communication can occur and to prompt discussion of how effective 
communication strategies could be used instead. As well, role plays were used extensively in pharmacistpatient dyads and also to demonstrate challenging pharmacist-health professional interactions utilising SBAR (Situation, Background, Assessment and Recommendation) and a Graded Assertiveness Approach (Lancman et al., 2015; Muller et al., 2018)

3. Peer and group evaluation: Within small groups, students assessed their peers' communication skills demonstrated in the role plays using CAT- based criteria, developed in previous research (Chevalier, 2017b). Pharmacy students assumed the role of either patient, pharmacist or assessor of the pharmacist's communication skills. Approximately 40-60 minutes of the two-hour tutorials were spent on role play activities. During this time, tutors would rotate among the small groups to provide feedback, answer questions, and engage students in discussion about their communication skills. Then, student groups volunteered to role play their scenarios to the larger tutorial group for further feedback.

\section{Survey development}

The survey was composed of three sections presented to Pharmacy students in the following order:

1. Demographics such as birthdate, gender, email address, education prior to Pharmacy school, Pharmacy work experience, and area of intern placement.

2. Thirty CAT-based, communication related statements identical for all three surveys. Level of agreement indicated using a 7-point Likert scale where Strongly Disagree equals ' 1 ' and Strongly Agree equals ' 7 '. The 30 communication statements were developed to represent communication behaviours based on the five CAT strategies, contextualised to the pharmacy setting and consistent with effective pharmacist-patient communication (Berger, 2009; Chevalier, 2017b). Two pharmacists on the research team provided face and content validity to ensure the Pharmacy-related content of the statements accurately reflected Pharmacy practice. A psychologist on the team with expertise in CAT-based health communication research verified the statements' relevance to CAT strategies.

3. Question/Comment section to respond to survey specific questions for Surveys \#2 and \#3 as well as an opportunity to provide any additional comments. In Survey \#2, students were asked, "Has participating in the communication skills' tutorials affected the way in which you will approach future medication counselling with patients? Please explain." In Survey \#3, students responded to the following: "How have you applied the communication skills learned in the communication tutorials of your final year in your current intern practice? If you find you haven't applied these skills, how are your current skills different from those learned in the tutorials?". The intent of these questions was to gain a deeper understanding of Pharmacy students' perspectives about their experience of the communication skills' tutorials and how their participation in the tutorials may or may not have influenced their communication approach with patients.

\section{Data analysis}

On-line surveys' results were downloaded from Checkbox Survey into an Excel database. Demographic results were descriptively analysed. Responses to the retained 26 statements were tabulated and expressed as a percentage of all positive responses (Agree plus Strongly Agree) for that particular statement. Question responses and comments were thematically analysed as described in the literature (Braun \& Clarke, 2006).

Nonparametric tests were employed in data analysis as data were not normally distributed. Differences between participants' responses over time were measured and analysed using SPSS (version 25) (IBM, 2017). A $p$-value of less than 0.05 was considered statistically significant. Wilcoxon signed rank test was used to detect changes in students' responses from Survey \#1 to Survey \#2. Friedman test was used to investigate whether there was a change in students' responses over time from Survey \#1 to Survey \#3. Only data in which participants completed all three surveys were included in this latter analysis.

Exploratory factor analysis (EFA) and Cronbach alpha reliability testing of the 30 statement questionnaire was conducted using SPSS (Version 25) (IBM, 2017).

\section{Results}

A total of 134/171 (78\%) eligible final year Pharmacy students completed Survey\#1 while 113/134 (84\%) completed Survey \#2. For Survey \#3, the response rate was $28 \%(32 / 113)$. To demonstrate that Survey \#3 respondents were representative of the 113 student sample, comparisons were made between students who completed Survey \#3 $(n=32)$ and those who completed Surveys \#1 and \#2, but not \#3 (n=81). No demographic differences were found between these groups for age (determined by both Independent $t$ and Mann-Whitney $\mathrm{U}$ test), or gender, education prior to Pharmacy school, and Pharmacy work experience (determined by Chisquare goodness of fit test). In addition, the distribution of students' scores were compared for the same two groups, those who completed Surveys \#1 and \#2 but not \#3 ( $\mathrm{n}=81)$ versus those who completed all three surveys $(n=32)$. No statistically significant differences were detected in the distribution of students' scores between these two groups for the 26 responses in both Surveys \#1 and \#2 (determined by both Independent $t$ and MannWhitney U test). 
Figure 2: A timeline of the data collection and participation numbers



Pharmacy student demographics for those who completed Surveys \#1 and \#2 and those who completed Surveys \#1 to \#3 are depicted in Table I.

Table I: Pharmacy student demographics

\begin{tabular}{|c|c|c|}
\hline $\begin{array}{l}\text { Demographic } \\
\text { Characteristics }\end{array}$ & $\begin{array}{c}\text { Students who } \\
\text { completed } \\
\text { Surveys \#1 \& \#2 } \\
(n=113) \\
\text { Numbers }(\%)\end{array}$ & $\begin{array}{c}\text { Students who } \\
\text { completed } \\
\text { Surveys \#1 \& \#2 } \\
\text { \& \#3 }(n=32) \\
\text { Numbers }(\%)\end{array}$ \\
\hline \multicolumn{3}{|l|}{ Age (years) } \\
\hline $\begin{array}{r}\text { Mean }(\mathrm{SD}) \\
\text { Median \& range }\end{array}$ & $\begin{array}{c}23.2(1.9) \\
22.9 ; 20.7-31.0\end{array}$ & $\begin{array}{c}23.4(.4) \\
23.0 ; 21.7-31.0\end{array}$ \\
\hline Gender (Female) & $85(75)$ & $23(72)$ \\
\hline \multicolumn{3}{|c|}{ Education level prior to pharmacy school } \\
\hline High School (or equivalent) & $85(75)$ & $26(81)$ \\
\hline Some university & $12(11)$ & $2(6)$ \\
\hline BSc degree held & $16(14)$ & $4(13)$ \\
\hline \multicolumn{3}{|l|}{ Work experience } \\
\hline Community pharmacy only & $73(65)$ & $21(66)$ \\
\hline Hospital pharmacy only & $5(4)$ & $2(6)$ \\
\hline $\begin{array}{r}\text { Both community } \& \text { hospital } \\
\text { pharmacy }\end{array}$ & $18(16)$ & $6(19)$ \\
\hline $\begin{array}{r}\text { No work experience in } \\
\text { pharmacy }\end{array}$ & $17(15)$ & $3(9)$ \\
\hline \multicolumn{3}{|l|}{ Intern Site } \\
\hline Community pharmacy only & $\mathrm{N} / \mathrm{A}$ & $16(50)$ \\
\hline Hospital pharmacy only & N/A & $13(41)$ \\
\hline Other (Research; International) & $\mathrm{N} / \mathrm{A}$ & $2(6)$ \\
\hline No intern site & N/A & $1(3)$ \\
\hline
\end{tabular}

\section{Findings from the three surveys}

Final results comparing Pharmacy students' responses to the statements about communicating with patients at three points in time are shown in Table II. Interim analysis (Survey \#2) indicated a statistically significant change in $7 / 26(27 \%)$ of statements. Final analysis (Survey \#3) results indicated that 6/7 (86\%) retained significance, while an additional statement gained statistical significance from Survey \#1 to Survey \#3.

In Survey \#2, Pharmacy students were asked "Has participating in the communication skills tutorials affected the way in which you will approach future medication counselling with patients? Please explain". Most students answered "Yes" to this question and many provided details about how they felt their communication skills would change or have already changed as a result of participating in the tutorials. Four themes resonated with students (Table III) who would often include two to three of these themes within their responses.

In Survey \#3, participants were asked, "How have you applied the communication skills learned in the communication tutorials of your final year in your current Intern practice? If you find you haven't applied these skills, how are your current skills different from those learned in the tutorials?". General comments were also invited. Themed responses from 24/32 (75)\% of students completing Survey \#3 are shown in Table III. Two students remarked that they did not recall the material covered in the communication tutorials while two others provided feedback for future course content such as "...exit strategies (for when a patient is talking around in circles)...". Eight students did not provide comments.

\section{Validation of the CAT-based survey tool}

Exploratory factor analysis (EFA) was conducted as described by the following steps:

- First the underlying structure of 30 statement results from Survey \#2 ( $n=113)$ was confirmed suitable for exploratory factor analysis (EFA) using SPSS version 25 (IBM, 2017).

- Principal components analysis (PCA) was used to extract factors followed by oblique rotation using Oblimin rotation $($ delta $=0)$. Initial analysis indicated that four statements did not load well and were removed for subsequent analysis. Retention of the remaining 26 items was determined by Kaiser's criterion (eigenvalues above 1), inspection of the scree plot, and by the use of Horn's parallel analysis (Horn, 1965).

- Parallel analysis, considered the most accurate method in estimating the number of components, (Zwick \& Velicer, 1986; Hubbard \& Allen, 1987), involves comparing the size of eigenvalues obtained from PCA with those from a randomly generated data set of the same size. Factors retained are limited to those with eigenvalues exceeding the values obtained from the corresponding random data set. Parallel analysis conducted using the software developed by Watkins (2000) indicated one component only for the 26 items. No retained statements were negatively worded. 
Table II: Pharmacy students' survey responses - Survey \#1, 2 \& 3 (n=32)

\begin{tabular}{|c|c|c|c|c|c|c|}
\hline CAT Strategy & Survey Statement & $\begin{array}{l}\text { Survey } \\
\# 1 \\
(\% \\
\text { SA \& A) }\end{array}$ & $\begin{array}{l}\text { Survey } \\
\# 2 \\
(\% \\
\text { SA\& A) }\end{array}$ & $\begin{array}{l}\text { Wilcoxon } \\
\text { Signed } \\
\text { Ranks } \\
\text { Test }^{*}\end{array}$ & $\begin{array}{c}\text { Survey } \\
\# \mathbf{3} \\
(\% \\
\text { SA \& A) }\end{array}$ & $\begin{array}{l}\text { Friedman } \\
\text { Test }^{*}\end{array}$ \\
\hline \multirow[t]{4}{*}{ Approximation } & $\begin{array}{l}\text { I am comfortable changing the way that I speak- to match the patient's manner of } \\
\text { speaking - more casual or formal depending on patient's manner. }\end{array}$ & $75 \%$ & $69 \%$ & 0.81 & $78 \%$ & 0.98 \\
\hline & $\begin{array}{l}\text { When speaking with a patient from a similar background as mine, I will often use } \\
\text { the expressions/accents as they do. }\end{array}$ & $66 \%$ & $81 \%$ & 0.18 & $72 \%$ & 0.35 \\
\hline & $\begin{array}{l}\text { I make sure I slow down my speech when I'm speaking with a patient who speaks } \\
\text { slowly to me. }\end{array}$ & $66 \%$ & $78 \%$ & 0.82 & $75 \%$ & 0.56 \\
\hline & $\begin{array}{l}\text { When a patient speaks loudly to me, I also raise my voice to their level and check } \\
\text { with them to make sure they can hear me properly. }\end{array}$ & $25 \%$ & $50 \%$ & 0.02 & $50 \%$ & 0.15 \\
\hline \multirow[t]{6}{*}{$\begin{array}{l}\text { Discourse } \\
\text { Management }\end{array}$} & $\begin{array}{l}\text { Patients need time to process information I give them, and then come up with any } \\
\text { questions - so I make sure I don't rush them during counselling. }\end{array}$ & $66 \%$ & $69 \%$ & 0.60 & $81 \%$ & 0.85 \\
\hline & $\begin{array}{l}\text { I make sure conversations with patients are well paced - with enough pauses - so } \\
\text { that they can ask me questions. }\end{array}$ & $50 \%$ & $72 \%$ & 0.01 & $81 \%$ & 0.003 \\
\hline & $\begin{array}{l}\text { I ask patients open-ended questions to engage them in the conversation about their } \\
\text { medications. }\end{array}$ & $63 \%$ & $72 \%$ & 0.11 & $84 \%$ & 0.01 \\
\hline & $\begin{array}{l}\text { When I'm giving patients medication information, I often pause and prompt them } \\
\text { with a simple "OK?" or something similar so I know they understand. }\end{array}$ & $44 \%$ & $59 \%$ & 0.04 & $75 \%$ & 0.004 \\
\hline & $\begin{array}{l}\text { I believe that when patients are engaged in the conversation with a pharmacist, they } \\
\text { will have a better understanding of their medications. }\end{array}$ & $94 \%$ & $88 \%$ & 0.59 & $94 \%$ & 0.19 \\
\hline & $\begin{array}{l}\text { I am able to follow patients' non-verbal cues (nods, facial expressions, body } \\
\text { language) to tell if they are listening to information I am providing to them. }\end{array}$ & $66 \%$ & $72 \%$ & 0.19 & $88 \%$ & 0.10 \\
\hline \multirow[t]{6}{*}{$\begin{array}{l}\text { Emotional } \\
\text { Expression }\end{array}$} & $\begin{array}{l}\text { I am confident that patients can tell that I feel their worries and questions about their } \\
\text { medications are important to me. }\end{array}$ & $31 \%$ & $59 \%$ & 0.03 & $72 \%$ & 0.03 \\
\hline & $\begin{array}{l}\text { When patients are worried about their medications, I behave in a caring way to make } \\
\text { sure they know I understand their concerns. }\end{array}$ & $72 \%$ & $81 \%$ & 0.72 & $75 \%$ & 0.84 \\
\hline & $\begin{array}{l}\text { I feel confident in being able to appropriately handle a difficult emotional situation } \\
\text { with a patient. }\end{array}$ & $16 \%$ & $28 \%$ & 0.02 & $47 \%$ & 0.001 \\
\hline & I speak to all patients in a respectful and courteous manner. & $91 \%$ & $91 \%$ & 0.56 & $94 \%$ & 0.47 \\
\hline & $\begin{array}{l}\text { When speaking to patients, I use both verbal and non-verbal (E.g. smile, eye contact) } \\
\text { communication to demonstrate that I care about what they say. }\end{array}$ & $84 \%$ & $84 \%$ & 0.76 & $91 \%$ & 0.95 \\
\hline & $\begin{array}{l}\text { I encourage patients who seem worried to feel free to contact me or the pharmacy } \\
\text { should they have any further concerns about their medications. }\end{array}$ & $75 \%$ & $78 \%$ & 0.90 & $88 \%$ & 0.22 \\
\hline \multirow[t]{5}{*}{$\begin{array}{l}\text { Interpersonal } \\
\text { Control }\end{array}$} & $\begin{array}{l}\text { When I'm speaking with a patient, I adjust my physical position, so I am not } \\
\text { standing over them. }\end{array}$ & $63 \%$ & $75 \%$ & 0.12 & $75 \%$ & 0.45 \\
\hline & $\begin{array}{l}\text { I make sure patients know about other healthcare resources in their community they } \\
\text { should contact if they experience issues with their medications. }\end{array}$ & $34 \%$ & $47 \%$ & 0.06 & $53 \%$ & 0.17 \\
\hline & $\begin{array}{l}\text { When I'm speaking with patients about their medications, I aim to empower patients } \\
\text { to take responsibility for their own health. (e.g. self-monitor \& management plan for } \\
\text { side effects) }\end{array}$ & $56 \%$ & $63 \%$ & 0.45 & $78 \%$ & 0.64 \\
\hline & $\begin{array}{l}\text { I am able to respectfully redirect conversations back on topic after patients have } \\
\text { wandered off topic. }\end{array}$ & $31 \%$ & $41 \%$ & 0.2 & $56 \%$ & 0.09 \\
\hline & $\begin{array}{l}\text { I believe it is important to ask patients at the start of the conversation whether they } \\
\text { have any medication related questions or issues they would like to discuss. }\end{array}$ & $59 \%$ & $78 \%$ & 0.03 & $72 \%$ & 0.03 \\
\hline \multirow[t]{5}{*}{ Interpretability } & $\begin{array}{l}\text { I am careful about avoiding the use of medical terms that a patient might not } \\
\text { understand. }\end{array}$ & $84 \%$ & $91 \%$ & 0.67 & $88 \%$ & 0.085 \\
\hline & $\begin{array}{l}\text { I feel confident in being able to tell whether a patient understands the medication } \\
\text { information I am explaining to them. }\end{array}$ & $47 \%$ & $59 \%$ & 0.006 & $69 \%$ & 0.007 \\
\hline & $\begin{array}{l}\text { I feel it's important to understand a patients' background so you can adjust the } \\
\text { terminology you use when explaining medication information. }\end{array}$ & $72 \%$ & $78 \%$ & 0.33 & $75 \%$ & 0.75 \\
\hline & $\begin{array}{l}\text { Whenever I'm speaking with patients about their medications, I make changes in the } \\
\text { level of language used - depending on patients' background and understanding of } \\
\text { medical terms. }\end{array}$ & $78 \%$ & $88 \%$ & 0.19 & $91 \%$ & 0.48 \\
\hline & $\begin{array}{l}\text { I make sure I use easy to understand language and simple phrasing when I explain to } \\
\text { a patient how a medication works. }\end{array}$ & $91 \%$ & $81 \%$ & 0.59 & $91 \%$ & 0.25 \\
\hline
\end{tabular}


Cronbach alpha reliability testing was conducted to provide assurance of internal consistency of the 26 item Patient-Centred Communication Scale for Pharmacy Students. Cronbach alpha value calculated for this unidimensional scale was 0.93 , above the acceptable 0.70 or greater (Tavakol \& Dennick, 2011).

Table III: Pharmacy students' exemplar responses to Survey \#2 and Survey \#3 questions

Survey \#2 Question: "Has participating in the communication skills tutorials affected the way in which you will approach future medication counselling with patients? Please explain."

\begin{tabular}{|c|c|}
\hline Themes & Exemplars \\
\hline $\begin{array}{l}\text { Increased awareness } \\
\text { of own communication } \\
\text { skills }\end{array}$ & $\begin{array}{l}\text { “...tutorials have given me a greater outlook...the way } \\
\text { we communicate may affect a patient's understanding } \\
\text { and use of a medication.” Participant } 26\end{array}$ \\
\hline $\begin{array}{l}\text { Expanded/enhanced } \\
\text { communication skills }\end{array}$ & $\begin{array}{l}\text { “..... communication tutorial has provided me with } \\
\text { strategies or alternative ways to communication with } \\
\text { patients and their understanding of the medications } \\
\text { and goals for example when handing out the } \\
\text { dispensed medication, asking if there are any issues/ } \\
\text { concerns with the current medication or other } \\
\text { medication..." Participant } 65\end{array}$ \\
\hline $\begin{array}{l}\text { More flexible \& able } \\
\text { to adapt } \\
\text { communication }\end{array}$ & $\begin{array}{l}\text { “...It has given me more techniques to address } \\
\text { different types of patients, whether they be from } \\
\text { different backgrounds or ages..." Participant } 42\end{array}$ \\
\hline $\begin{array}{l}\text { Benefited from peer } \\
\text { learning }\end{array}$ & $\begin{array}{l}\text { “... Watching and participating in role plays is } \\
\text { definitely helpful and gaining feedbacks as well } \\
\text { [from peers]...” Participant } 45\end{array}$ \\
\hline $\begin{array}{l}\text { Unnecessary } \\
\text { repetition }\end{array}$ & $\begin{array}{l}\text { "Not overly, these points are already raised in the case } \\
\text { roleplay tutorials, and in the workplace." Participant } 6\end{array}$ \\
\hline
\end{tabular}

Survey \#3 Question: "How have you applied the communication skills learned in the communication tutorials of your final year in your current Intern practice? If you find you haven't applied these skills, how are your current skills different from those learned in the tutorials?'

Themes Exemplars

Application of patient “...I believe that the communication skills I have learned centred from the communication tutorials have helped me communication skills immensely in terms of providing a patient-centred care, (individualised/tailored/ especially in making individualized interactions with the patient specific patient depending on key patient factors." Participant 73 approaches in their interactions; having effective but difficult conversations)

"I applied my skills learned back in final year tutorial to handle difficult situation e.g. dealing with customers who is angry and rushing." Participant 63

Reflection

“... this survey reminded me of some the things we (completion of survey learnt and the importance of them in communicating caused respondents to with patients. It has given me some things to reflect on reflect on current my current practice and some ways I can improve my practice) communication with patients." Participant 113

Practice environment challenges

(noise, busyness and limited workspace)

"To apply the skills learnt in the tutorials is actually more difficult in the workplace... a busy environment and a lack of staff...no proper counselling rooms which doesn't provide any privacy to the customer - this may mean they are less likely to ask questions as they can be overheard... customers are in a rush or they've waited too long and don't want to spend more time listening to what you have to say." Participant 65

communication skills

\section{Discussion}

The impact of three, theory-based communication skills tutorials on Pharmacy students' self-reported attitudes, beliefs and behaviours in communicating with patients was investigated in this longitudinal study. To the best of the authors' knowledge, this is novel Pharmacy education research that investigates these effects at three different points in time, pre-post tutorials and then again several months into Pharmacy students' intern year. Results indicated some key areas of change from baseline (Survey \#1) to post tutorials (Survey \#2) that appear to be sustained well into Pharmacy students' intern year (Survey \#3).

Changes in students' responses from Survey \#1 to Survey \#2 and their comments about the effects of participating in the tutorials (Table II) reflect their growing awareness of and knowledge gained in using CAT strategies in patient communication. Then, results from Survey \#2 to Survey \#3 provided valuable information about the sustainability of skills learned in the tutorials and how students perceived they had, or had not, used these skills post-graduation (Table II). At Survey \#2, Pharmacy students indicated stronger agreement for seven of the communication statements after the tutorials were held, and then maintained or increased their level of agreement for six of these seven statements by Survey \#3.

Agreement had increased with one discourse management statement about asking open-ended questions to engage patients in conversation from Survey \#1 to Survey \#3, but not immediately after completion of the tutorials (Survey \#2). Perhaps, simply having more exposure and experience in conversations with patients within their internship demonstrated the value of using open-ended questions and increased their overall confidence in patient interactions. The benefit of time and experience in improving communication skills was suggested by students (Table III). There was increased agreement by Survey \#2 that conversations with patients should be adequately paced to allow time for questions. In a study where patients were asked what made conversations with pharmacists about their medications effective, many indicated the importance of having time to ask questions and have their issues addressed. One elderly man stated, "...the patient needs to be not rushed" (Chevalier et al., 2018). Pharmacy students increased their agreement for another discourse management statement about engaging patients by pausing in conversations and prompting patients for a response. These significant changes occurred at both time points (Survey \#2 and \#3). This approach in medication counselling has been previously described as "chunk and check" (Greenhill et al., 2011).

For the approximation statements, students' level of agreement was higher from Survey \#1 to \#2 for only one statement about adjusting their voice volume to match a patient's. It is possible that students were not conscious of doing so prior to participating in the tutorials. This has been reported by Gasiorek (2012) where speakers may make unconscious adaptations to their speech production. However, this change was not statistically significant by 
Survey \#3. As alluded to in students' comments (Table III), the busyness and lack of privacy in some stores may have inhibited them from speaking louder to patients.

Changes in students' level of agreement to two emotional expression statements had further increased at Survey \#3 after several months practicing as an intern. One statement implies an increase in students' confidence to convey empathy to patients. This rise in empathy contrasts with a study measuring changes in empathy scores of health professional students before and after their first year of training, in which empathy had declined for all programmes including Pharmacy (Nunes et al., 2011). In another study, fourth year pharmacy students received empathy training within their communication skills course and completed the La Monica Empathy Profile before and after completing the course. Researchers found increased students' scores on two of the five modes "perceiving feelings and listening" and "respect of self and others" after taking the course, and believed that these changes in Pharmacy students' self-reported empathic attitudes and behaviours may be related to their empathy training (Lonie et al., 2005). The rationale for empathy as a key component of Pharmacy students' communication skills training is well founded as researchers have found that many patients place importance on feeling valued and heard by pharmacists (Braaf et al., 2015; Morecroft, Thornton, \& Caldwell, 2015; Chevalier et al., 2018).

The second emotional expression statement with significant increases in agreement are related to students' growing confidence in patient interactions and their ability to handle challenging situations effectively. Including role play scenarios with "angry" or "impatient" patients in the communication skills tutorials allowed students to experiment with different approaches in diffusing situations. Students indicated their appreciation of practicing these difficult conversations in their Survey \#2 comments. Pharmacy education research supports Pharmacy student preference for communication skills training that included "developing training with outcomes that are transferable into real-life practice" (Svensberg et al., 2018: p.158).

In one interpersonal control statement about the importance of involving patients in the agenda-setting stage of a conversation, students' attitudes increased significantly after the tutorials, and these views were held into their intern year. It is heartening to see students emphasise this patient-centred practice as it contrasts to that observed in other studies where pharmacists in practice rarely engaged patients in agenda-setting (Braaf et al., 2015; Chevalier et al., 2017a).

A change in one interpretability related statement held from Survey \#1 to Survey \#3 may be demonstrating students' gained confidence in competently conveying information that is understood by patients. However, compared to other CAT strategies, fewer increases were noted in interpretability statements. This likely reflects Pharmacy schools' instruction that emphasises the use of non-medical terms and easy to understand information (Kimberlin, 2006; Berger, 2009). For communication statements that showed high agreement and little change over time, it is possible that students who agreed with the statements probably understood the value of these communication behaviours and used them in their practice already.

A theory-based patient-centred communication questionnaire for Pharmacy students has been developed - an important step forward. This questionnaire was validated in the UQ setting using EFA and Cronbach reliability testing. It was not surprising that the 26 items retained in the EFA loaded well onto one factor, rather than five factors related to the CAT strategies on which the 26 items are based. Although these CAT strategies measure different aspects of communication, they are typically not independent or orthogonal components. For example, a speaker may redirect a conversation to keep another person engaged in the exchange (discourse management strategy) or because the subject is a sensitive issue and the choice to do so is an act of kindness (emotional expression). Previous research has described these links between CAT strategies and their pursuant communication behaviours and has suggested that these are related to the multiple goals held by speakers for their interaction, and that these can shift as the conversation progresses (Dragojevic et al., 2015; Chevalier, 2017b).

This patient-centred communication questionnaire explicitly describes patient-centred communication behaviours whereas many other Pharmacy research tools assess communication skills by verifying whether students have completed specific activities (Rogers \& King, 2012; Adrian, Zeszotarski, \& Ma, 2015; Grice et al., 2017) or focusing on only one aspect of communication such as empathy (Lonie et al., 2005) rather than looking at how students are accomplishing these activities. It is also possible that the tool's explicit depiction of communication behaviours may encourage more self-reflection by students as noted in some of comments (Table III). Learning advantages for health professional students by incorporating reflective thinking in their training has been described in the literature (Tsingos, Bosnic-Anticevich, \& Smith, 2014).

There are limitations to this study. Response rate to Survey \#3 was low; however, additional analysis demonstrated that this group was not statistically different from the larger cohort of Survey \#2. Pharmacy students' communication behaviours were self-reported and not observed in this study. Although survey responses were anonymous, students may have provided socially desirable responses when they self-reported their attitudes, beliefs and behaviours in communicating with patients. As well, it is possible that students may not have recalled details about communication skills learned in the tutorials when completing Survey \#3. Because this study was conducted at a single university, the results might not be generalisable to other Pharmacy programmes in other universities. In addition, a number of confounders exist regarding Pharmacy students' communication skills training such as the influence of other tutorials, courses or preceptors in their intern year. However, Survey \#2 
and \#3 asked students specifically, whether and how, these particular tutorials may have influenced their communication with patients.

The strengths of this study are that it is theory-based and its longitudinal design captures Pharmacy students' self-reported attitudes, beliefs and behaviours about patient communication over time. Using CAT as the theory underpinning the three tutorials provided students with insight into why communication behaviours occur, and why miscommunication is common. These transferable skills will inform students' learnings in many types of professional interactions.

Recommendations for future research include investigating the impact of Pharmacy students' CATbased communication skills training at multiple sites (Pharmacy schools) using a randomised control design to reduce the effect of study confounders. As well, videotaping pharmacist-patient role play scenarios would provide additional validity to the communication behaviours self-reported by Pharmacy students.

This novel, longitudinal study examined Pharmacy students' self-reported attitudes, beliefs and behaviours about patient communication before and after theorybased tutorials and post-graduation. Students indicated growing awareness of key communication behaviours emphasised in tutorials. Most of these behaviours were retained or increased in value at post-graduation. A patient-centred communication questionnaire for Pharmacy students has been developed for future research and can be made available for other interested universities to use and validate in their settings.

\section{References}

Adrian, J.A.L., Zeszotarski, P., \& Ma, C. (2015). Developing pharmacy student communication skills through role-playing and active learning. American Journal of Pharmaceutical Education, 79(3), Art.44. doi: https:// doi.org/10.5688/ajpe79344

Babinec, P.M., Rock, M.J., Lorenzetti, D.L., \& Johnson, J.A. (2010). Do researchers use pharmacists' communication as an outcome measure? A scoping review of pharmacist involvement in diabetes care. International Journal of Pharmacy Practice, 18(4), 183-193. doi: https:// doi.org/10.1111/j.2042-7174.2010.00038.x

Berger, B. (2009). Communication skills for pharmacists: building relationships, improving patient care (3rd ed.). Washington, DC, US: American Pharmacists Association

Blom, L., Wolters, M., ten Hoor-Suykerbuyk, M., van Paassen, J., \& van Oyen, A. (2011). Pharmaceutical education in patient counseling: $20 \mathrm{~h}$ spread over 6 years? Patient Education and Counseling, 83(3), 465-471. doi: https://doi.org/10.1016/j.pec.2011.05.018
Braaf, S., Rixon, S., Williams, A., Lieu, D., \& Manias, E. (2015). Pharmacist-patient medication communication during admission and discharge in specialty hospital settings: implications for person centered healthcare. International Journal of Person Centered Medicine, 4(2), 90-105. doi: https://doi.org/10.5750/ijpcm.v4i2.446

Braun, V., \& Clarke, V. (2006). Using thematic analysis in psychology. Qualitative Research in Psychology, 3, 77-101

Buring, S.M., Kirby, J., \& Conrad, W.F. (2007). A structured approach for teaching students to counsel selfcare patients. American Journal of Pharmaceutical Education, 71, Art.8. doi: https://doi.org/10.5688/ aj710108

Campbell, D.T., \& Cook, T.D. (1979). Quasiexperimentation: Design \& analysis issues for field settings. Chicago: Rand McNally College Publishing Company

Canadian Pharmacists' Association. (2018). Pharmacists' Expanded Scope of Practice (online) Available at: https:// www.pharmacists.ca/pharmacy-in-canada/scope-ofpractice-canada/. Accessed 15, April, 2020

Checkbox6 (Version 2017Q2). (2017). Watertown, MA, USA: Checkbox Survey, Inc. (online). Available at: https://www.checkbox.com/

Chevalier, B.A., Watson, B.M., Barras, M.A., \& Cottrell, W.N. (2017a). Investigating Strategies Used by Hospital Pharmacists to Effectively Communicate with Patients during Medication Counselling. Health Expectations, 20, 1121-1132. doi: https://doi.org/10.1111/ $\underline{\text { hex.12558 }}$

Chevalier, B. (2017b). Investigating the effectiveness of communication taking place between hospital pharmacists and patients during medication counselling. Doctoral dissertation, The University of Queensland, Brisbane, Australia. Available at: https://espace.library. uq.edu.au/view/UQ:689054. Accessed 15 April, 2020

Chevalier, B.A., Watson, B.M., Barras, M.A., \& Cottrell, W.N. (2018). Hospital pharmacists' and patients' views about what constitutes effective communication between pharmacists and patients. International Journal of Pharmacy Practice, 26, 450-457. doi: https://doi.org/10.1111/ijpp.12423

Coupland, N., Coupland, J., Giles, H., \& Henwood, K. (1988). Accommodating the elderly: Invoking and extending a theory. Language in Society, 17(1), 1-41. https://www.jstor.org/stable/4167896?seq=1\#page_scan tab contents

Dragojevic, M., Giles, H., \& Gasiorek, J. (2015). Communication accommodation theory. In The international encyclopedia of interpersonal communication, (eds. C. Berger \& M. Roloff), Hoboken, New Jersey, US: John Wiley \& Sons, Inc. pp. 1-21. doi: https://doi.org/ 10.1002/9781118540190.wbeic006 
Gasiorek, J., \& Giles, H. (2012). Effects of Inferred Motive on Evaluations of Nonaccommodative Communication. Human Communication Research, 38, 309-331. doi: https://doi.org/10.1111/j.1468-2958. 2012.01426.X

Giles H. (2008). Communication accommodation theory. In Engaging theories in interpersonal communication: Multiple perspectives, (eds. L.A. Baxter, D.O. Braithewaite). Thousand Oaks, CA, US: Sage Publications, Inc. pp. 161-173

Greenhill, N., Anderson, C., Avery, A., \& Pilnick, A. (2011). Analysis of pharmacist-patient communication using the Calgary-Cambridge guide. Patient Education and Counseling, 83(3), 423-431. doi: https://doi.org/ 10.1016/j.pec.2011.04.036

Grice, G.R., Gattas, N.M., Prosser, T., Voorhees, M., Kebodeaux, C., Tiemeier, A., Berry, T.M., Wilson, A.G., Mann, J., \& Juang, P. (2017). Design and validation of patient-centered communication tools $(\mathrm{PaCT})$ to measure students' communication skills. American Journal of Pharmaceutical Education, 81(8), 5927. doi: https:// doi.org/10.5688/ajpe5927

Hardin, H.C., Hall, A.M., Roane, T.E., \& Mistry, R. (2012). An advanced pharmacy practice experience in a student-staffed medication therapy management call center. American Journal of Pharmaceutical Education, 76(6), Art.110. https://doi.org/10.5688/ajpe766110

Horn, J.L. (1965). A rationale and test for the number of factors in factor analysis. Psychometrika, 30, 179-185. doi: https://doi.org/10.1007/BF02289447

Hubbard, R., \& Allen, S.J. (1987). An empirical comparison of alternative methods for principal component extraction. Journal of Business Research, 15 (2), 173 - 190 . doi: https://doi.org/ $\underline{10.1016 / 0148-2963(84) 90047-X}$

Hyvärinen, M.-L., Tanskanen, P., Katajavuori, N., \& Isotalus, P. (2008). Feedback in patient counselling training-Pharmacy students' opinions. Patient Education and Counseling, 70(3), 363-369. doi: https:// doi.org/10.1016/j.pec.2007.11.005

IBM, C. (2017). IBM SPSS Statistics for Windows (Version Version 25.0). Armonk, NY: IBM Corp.

Jin, H.K., Choi, J.H., Kang, J.E., \& Rhie, S.J. (2018). The effect of communication skills training on patientpharmacist communication in pharmacy education: a meta-analysis. Advances in Health Sciences Education, 23,633-652. doi: https://doi.org/10.1007/ s10459-017-9791-0

Jones, L., Woodhouse, D., \& Rowe, J. (2007). Effective nurse parent communication: A study of parents' perceptions in the NICU environment. Patient Education and Counseling, 69(1-3), 206-212. doi: https://doi.org/ 10.1016/j.pec.2007.08.014

Kaddoura, M. (2013). Think pair share: A teaching learning strategy to enhance students' critical thinking. Educational Research Quarterly, 36(4), 3-24
Kairuz, T., Noble, C., \& Shaw, J. (2010). Preceptors, interns, and newly registered pharmacists' perceptions of new zealand pharmacy graduates' preparedness to practice. American Journal of Pharmaceutical Education, 74(6), Art.108. doi: https://doi.org/10.5688/ aj7406108

Katoue, M.G., \& Al Haqan, A. (2013). Implementation and evaluation of a workshop on patient counseling about antidiabetic medications for final-year pharmacy students. Medical Principles and Practice, 22(5), 489-494. doi: https://doi.org/10.1159/000350840

Kimberlin, C.L. (2006). Communicating with patients: skills assessment in US colleges of pharmacy. American Journal of Pharmaceutical Education, 70(3), Art.67. doi: https://doi.org/10.5688/aj700367

Lancman B., Jorm C., Iedema R., Piper D., \& Manidis M. (2015). Taking the heat in critical situations: being aware, assertive and heard. In Communicating quality and safety in health care, (eds. R. Iedema, D. Piper, \& M. Manidis). Melbourne, Australia: Cambridge University Press. pp, 268-279

Law, M.R., Ma, T., Fisher, J., \& Sketris, I.S. (2012). Independent pharmacist prescribing in Canada. Canadian Pharmacists Journal, 145(1), 17-23. e11. doi: https:// doi.org/10.3821/1913-701X-145.1.17

Lonie, J.M., Alemam, R., Dhing, C., \& Mihm, D. (2005). Assessing Pharmacy Student Self-Reported Empathic Tendencies. American Journal of Pharmaceutical Education, 69(2). doi: https://doi.org/10.5688/aj690229

Morecroft, C., Thornton, D., \& Caldwell, N. (2015). Inpatients' expectations and experiences of hospital pharmacy services: Qualitative study. Health Expectations, 18(5), 1009-1017. doi: https://doi.org/ $\underline{10.1111 / \text { hex.12074 }}$

Muller M., Jurgens J., Redaelli M., Klingberg K., Hautz W.E. \& Stock S. (2018). Impact of the communication and patient hand-off tool SBAR on patient safety: a systematic review. British Medical Journal Open, 8(8), e 022202 . doi: https://doi.org/10.1136/ bmjopen-2018-022202

Murad, M.S., Chatterley, T., \& Guirguis, L.M. (2014). A meta-narrative review of recorded patient-pharmacist interactions: exploring biomedical or patient-centered communication? Research in Social and Adminstrative Pharmacy, 10(1), 1-20. doi: https://doi.org/10.1016/ j.sapharm.2013.03.002

Nunes, P., Williams, S., Sa, B., \& Stevenson, K. (2011). A study of empathy decline in students from five health disciplines during their first year of training. International Journal of Medical Education, 2, 12-17. doi: https://doi.org/10.5116/ijme.4d47.ddb0

O’Brien, C.E., Flowers, S.K., \& Stowe, C.D. (2017). Desirable Skills in New Pharmacists: A Comparison of Opinions From Practitioners and Senior Student Pharmacists. Journal of Pharmacy Practice, 30(1), 94-98. doi: https://doi.org/10.1177/0897190015621804 
Pharmaceutical Society of Australia. (2017). Professional Practice Standards - Version 5. Pharmaceutical Society of Australia (online). Available at: https:// www.psa.org.au/wp-content/uploads/2018/08/ Professional-Practice-Standards-v5.pdf. Accessed 15 April, 2020

Rogers, E.R., \& King, S.R. (2012). The influence of a patient-counseling course on the communication apprehension, outcome expectations, and self-efficacy of first-year pharmacy students. American Journal of Pharmaceutical Education, 76(8), Art.152. doi: https:// doi.org/10.5688/ajpe768152

Svensberg, K., Sporrong, S. K., Lupattelli, A., Olsson, E., Wallman, A., \& Björnsdottir, I. (2018). Nordic Pharmacy Students' Opinions of their Patient Communication Skills Training. American Journal of Pharmaceutical Education, 82(2), 6208. doi: https://doi.org/10.5688/ ajpe 6208

Tavakol, M., \& Dennick, R. (2011). Making sense of Cronbach's alpha. International Journal of Medical Education, 2, 53-55. doi: https://doi.org/10.5116/ijme. $\underline{4 \mathrm{dfb}} .8 \mathrm{dfd}$

Tonna, A.P., Stewart, D., West, B., \& McCaig, D. (2007). Pharmacist prescribing in the UK - a literature review of current practice and research. Journal of Clinical Pharmacy and Therapeutics, 32(6), 545-556. doi: https:// doi.org/10.1111/j.1365-2710.2007.00867.x

Trujillo, J.M., McNair, C.D., Linnebur, S.A., Valdez, C., $\&$ Trujillo, T.C. (2016). The Impact of a Standalone, Patient-centered Communication Course Series on Student Achievement, Preparedness, and Attitudes. American Journal of Pharmaceutical Education, 80(10), 174. doi: https://doi.org/10.5688/ajpe8010174

Tsingos, C., Bosnic-Anticevich, S., \& Smith, L. (2014). Reflective practice and its implications for pharmacy education. American Journal of Pharmaceutical Education, 78(1), Art.18: https://doi.org/10.5688/ ajpe 78118

Watkins, M.W. (2006). Determining Parallel Analysis Criteria. Journal of Modern Applied Statistical Methods, 5(2), 344-346. doi: https://doi.org/10.22237/jmasm/ $\underline{1162354020}$

Watson, B.M., \& Gallois, C. (1999). Communication accommodation between patients and health professionals: themes and strategies in satisfying and unsatisfying encounters. International Journal of Applied Linguistics, 9(2), 167-180. doi: https://doi.org/10.1111/j. 1473-4192.1999.tb00170.x

World Health Organisation. (2003). Adherence to LongTerm Therapies - Evidence for action (online). Available at: http://www.who.int/chp/knowledge/publications/ adherence_report/en/. Accessed 12 February, 2020

Zolnierek, K.B., \& Dimatteo, M.R. (2009). Physician communication and patient adherence to treatment: a meta-analysis. Medical Care, 47(8), 826-834. doi: https:// doi.org/10.1097/MLR.0b013e31819a5acc
Zwick, W.R., \& Velicer, W.F. (1986). Comparison of five rules for determining the number of components to retain. Psychological Bulletin, 99(3), 432-442. doi: https://doi.org/10.1037/0033-2909.99.3.432 